Linda Z. Holland • Tyamagondlu V. Venkatesh

Andrew Gorlin • Rolf Bodmer • Nicholas D. Holland

\title{
Characterization and developmental expression of AmphiNk2-2, an NK2 class homeobox gene from amphioxus (Phylum Chordata; Subphylum Cephalochordata)
}

Received: 24 November 1997 / Accepted: 2 February 1998

\begin{abstract}
The genome of amphioxus includes Amph$i N k 2-2$, the first gene of the NK2 homeobox class to be demonstrated in any invertebrate deuterostome. Amph$i N k 2$-2 encodes a protein with a TN domain, homeodomain, and NK2-specific domain; on the basis of amino acid identities in these conserved regions, AmphiNk2-2 is a homolog of Drosophila vnd and vertebrate Nkx2-2. During amphioxus development, expression of Amph$i N k 2-2$ is first detected ventrally in the endoderm of late gastrulae. In neurulae, endodermal expression divides into three domains (the pharynx, midgut, and hindgut), and neural expression commences in two longitudinal bands of cells in the anterior neural tube. These neural tube cells occupy a ventrolateral position on either side of the cerebral vesicle (the probable homolog of the vertebrate diencephalic forebrain). The dynamic expression patterns of AmphiNkx2-2 suggest successive roles, first in regionalizing the endoderm and nervous system and later during differentiation of specific cell types in the gut (possibly peptide endocrine cells) and brain (possibly including axon outgrowth and guidance).
\end{abstract}

Key words NK2 homeobox · Amphioxus · Brain · Gut

\section{Introduction}

Genes of the NK2 class have a distinctive homeobox (Bürglin 1994) and are transcribed in the developing gut, nervous system and heart of insects and vertebrates. Expression patterns of some NK2 genes have recently suggested possible homologies between invertebrate and vertebrate hearts and between regions of invertebrate and

Edited by D. Tautz

L.Z. Holland · N.D. Holland (

Division of Marine Biology, Scripps Institution of Oceanography, La Jolla, CA 19093-0202, USA

T.V. Venkatesh · A. Gorlin · R. Bodmer

Department of Biology, University of Michigan,

Ann Arbor, MI 48109-1048, USA vertebrate nervous systems. Specifically, Drosophila tin (tinman) (NK4) and vertebrate $N k x 2-5$ initiate heart differentiation on the dorsal and ventral side of the embryo, respectively (Bodmer 1993, 1995), while Drosophila vnd (ventral nervous system defective) (NK2) and vertebrate $N k x 2-2$ appear to function similarly to regionalize the nervous system on the ventral and dorsal sides of the embryo, respectively (Bier 1997). Such inverse relationships between body parts expressing homologous developmental genes are consistent with a reversal of the dorsoventral axis between Drosophila and vertebrates (François and Bier 1995; Jones and Smith 1995; De Robertis and Sasai 1996) and have revived evolutionary scenarios deriving the vertebrates from ancestors with annelid-like or arthropod-like body plans.

NK2 class genes encode proteins that have a tyrosine at homeodomain position 54 and are often further characterized by two highly conserved motifs in addition to the homeodomain. The first of these motifs (the TN domain) comprises 12 amino acids near the amino terminus, and the second (the NK2-specific domain) is a 19-amino acid sequence not far downstream from the homeodomain (Harvey 1996). Genes of the NK2 class, although best studied for Drosophila and for vertebrates, have also been found in sponges (Seimiya et al. 1994), cnidarians (Grens et al. 1996), flatworms (Garcia-Fernàndez et al. 1991), nematodes (Okkema and Fire 1994), and annelids (Nardelli-Haefliger and Shankland 1993).

To date, no gene of the NK2 class has been described from any invertebrate deuterostome, a group comprising the echinoderms, hemichordates, tunicates, and amphioxus. Studies of NK2 class genes in amphioxus are of special interest, because amphioxus is widely believed to be the closest living invertebrate relative of the vertebrates (Wada and Satoh 1994) and is a useful proxy for the immediate ancestor of the vertebrates. The present paper is the first demonstration of any NK2 class gene from amphioxus. On the basis of its structure, this gene (AmphiNk2-2) is homologous to Drosophila vnd (Jiménez et al. 1995; Nierenberg et al. 1995) and vertebrate Nkx2-2 (Price et al. 1992; Saha et al. 1993; Rud- 
nick et al. 1994; Barth and Wilson 1995; Shimamura et al. 1995; Hartigan and Rubenstein 1996). Like its homologs in Drosophila and vertebrates, amphioxus Amph$i N k 2-2$ is expressed in the developing gut and central nervous system. The results suggest that AmphiNkx2-2 may function early in development for regionalization of the gut and central nervous system and might later be involved in the differentiation of specific cell types.

\section{Materials and methods}

Adult males and females of the Florida amphioxus (Branchiostoma floridae) were collected during the summer breeding season in Tampa Bay, Florida. Eggs obtained from electrically stimulated females were fertilized, and the developmental stages were raised in laboratory culture according to Holland and Holland (1993).

Polymerase chain reaction (PCR) was used to amplify the NK homeodomain sequence from genomic DNA pooled from 20 adults of $B$. floridae. The degenerate primers corresponded to the first and third helices of the NK homeodomain of Drosophila Nk4 and mouse Nkx2-5. The forward primer sequence, coding for AQFVFELEV, was CA(GA)GC(N)CA(GA)GT(N)TA(TC)GA (AG)CT(N)GA, and the reverse primer sequence, coding for TQVKIWFQN, was AG(CT)(CT)TG(AG)AACCA(AGT)AT(CT) TT(N)AC(CT)TG(N)GT. For PCR, $500 \mathrm{ng}$ of genomic DNA from B. floridae was used in a $50 \mu \mathrm{l}$ reaction with $1 \mathrm{mg}$ primer, $200 \mathrm{nM}$ dNTPs, $1.5 \mathrm{mM} \mathrm{Mg}{ }^{++}$, and 1 unit of Taq polymerase. After a 4 min denaturation at $91{ }^{\circ} \mathrm{C}$, samples passed through 30 cycles, each consisting of $30 \mathrm{~s}$ at $90^{\circ} \mathrm{C}, 30 \mathrm{~s}$ at $40^{\circ} \mathrm{C}$, and $30 \mathrm{~s}$ at $90^{\circ} \mathrm{C}$. After cycling, samples were incubated for $7 \mathrm{~min}$ at $72^{\circ} \mathrm{C}$ to complete synthesis of PCR products. When run on an agarose gel, the reaction products included a single band of expected size (120 bp). DNA from this band was cloned (TA cloning kit, Invitrogen, Carlsbad, Calif.), and plasmid DNA from 10 clones was purified and sequenced.

Fig. 1A-C Amino acid sequences of homeodomain (A), TN domain (B), and NK2-specific domain (C) of amphioxus AmphiNk2-2 compared to corresponding domains encoded by related NK2 class genes of mouse (Nkx2-2 from Hartigan and Rubenstein 1996; Nkx2-1 from Guazzi et al. 1990), zebrafish (ZNk2-2 from Barth and Wilson 1995), Xenopus (XeNk-2 from Harvey 1996), and Drosophila (vnd from Jiménez et al. 1995; Nierenberg et al. 1995). For each conserved domain, identical amino acids are indicated by dashes; percentages of identical amino acids are given on the right. Predicted helical stretches of homeodomain amino acids are underlined
The PCR clone most closely matching the homeodomain of mouse Nkx 2.5 was used to probe a cDNA library in Lambda Zap II (Stratagene Inc., La Jolla, Calif.) made from pooled 2- to 4-day larvae of B. floridae (Holland et al. 1996). Approximately $4 \times 10^{5}$ plaques were screened at low stringency. Filters were hybridized at $37^{\circ} \mathrm{C}$ in $35 \%$ formamide, $6 \times \mathrm{SSPE}$ (IM NaCl, $60 \mathrm{mM}$ $\mathrm{NaH}_{2} \mathrm{PO}_{4}, 6 \mathrm{mM}$ EDTA, $\mathrm{pH} 7.4$ ), $0.1 \%$ sodium dodecyl sulfate (SDS), $1 \%$ dry milk powder and washed three times at room temperature in $0.2 \times$ SSPE with $0.1 \%$ SDS. The screen yielded one strongly positive and two weakly positive clones, which were sequenced with the AmpliTaq FS sequencing kit (Perkin Elmer, Branchburg, N.J.). One of the weakly positive clones (AmphiNkx22) had a homeobox sequence closely matching that of mouse Nkx2-2.

Developmental expression of $N k x 2-2$ was studied by in situ hybridizations of amphioxus embryos and larvae. The template for antisense riboprobe synthesis, which averaged about 1,600 bp, was a full-length cDNA of $N k \times 2-2$ linearized at the $5^{\prime}$ end. Methods for riboprobe synthesis, whole-mount in situ hybridization, and histological preparation were according to Holland et al. (1996).

\section{Results and discussion}

The AmphiNk2-2 cDNA sequence from B. floridae is recorded in GenBank (accession number AF032999). The 2312-bp sequence includes the $5^{\prime}$ UTR, the coding region, and a long $3^{\prime}$ untranslated region (UTR) not ending in a polyadenylation signal. If one assumes that translation starts at the first ATG downstream from the in-frame stop codon, the longest open reading frame encodes 312 amino acids and ends at a stop codon. The protein includes a TN domain, a homeodomain, and an NK2-specific domain, which closely resemble the corresponding domains of vertebrate Nkx2-2 and Drosophila vnd (Fig. 1). Conserved domains encoded by other genes of the NK2 class (e.g. mouse Nkx2-1 in Fig. 1) share markedly fewer identical amino acids with the conserved domains of AmphiNk2-2.

During amphioxus development, expression of Amph$i N k 2-2$ is first detected by in situ hybridization in late gastrulae ( $8 \mathrm{~h}$ after fertilization) throughout the anteroventral endoderm of the hypoblast (Fig. 2A, B). At this and subsequent stages, AmphiNk2-2 is not expressed in the most posterior hypoblast. In early neurulae $(10 \mathrm{~h})$, as the epidermis is overgrowing the neural plate, expression remains strong throughout much of the ventral endoderm

A

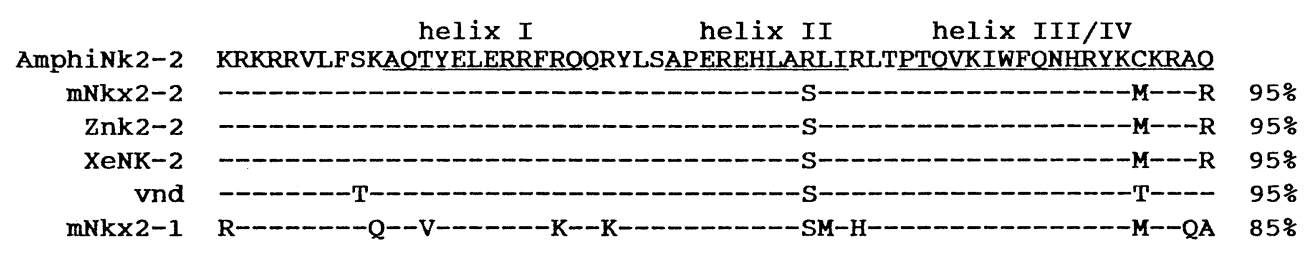

$\mathbf{B}$

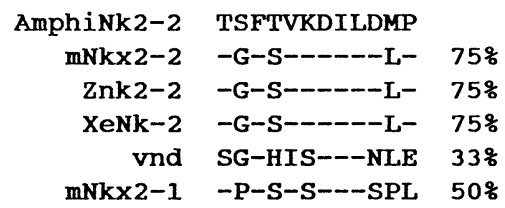

C

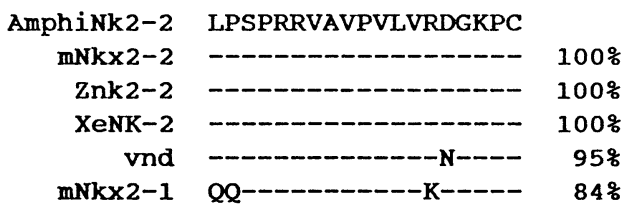



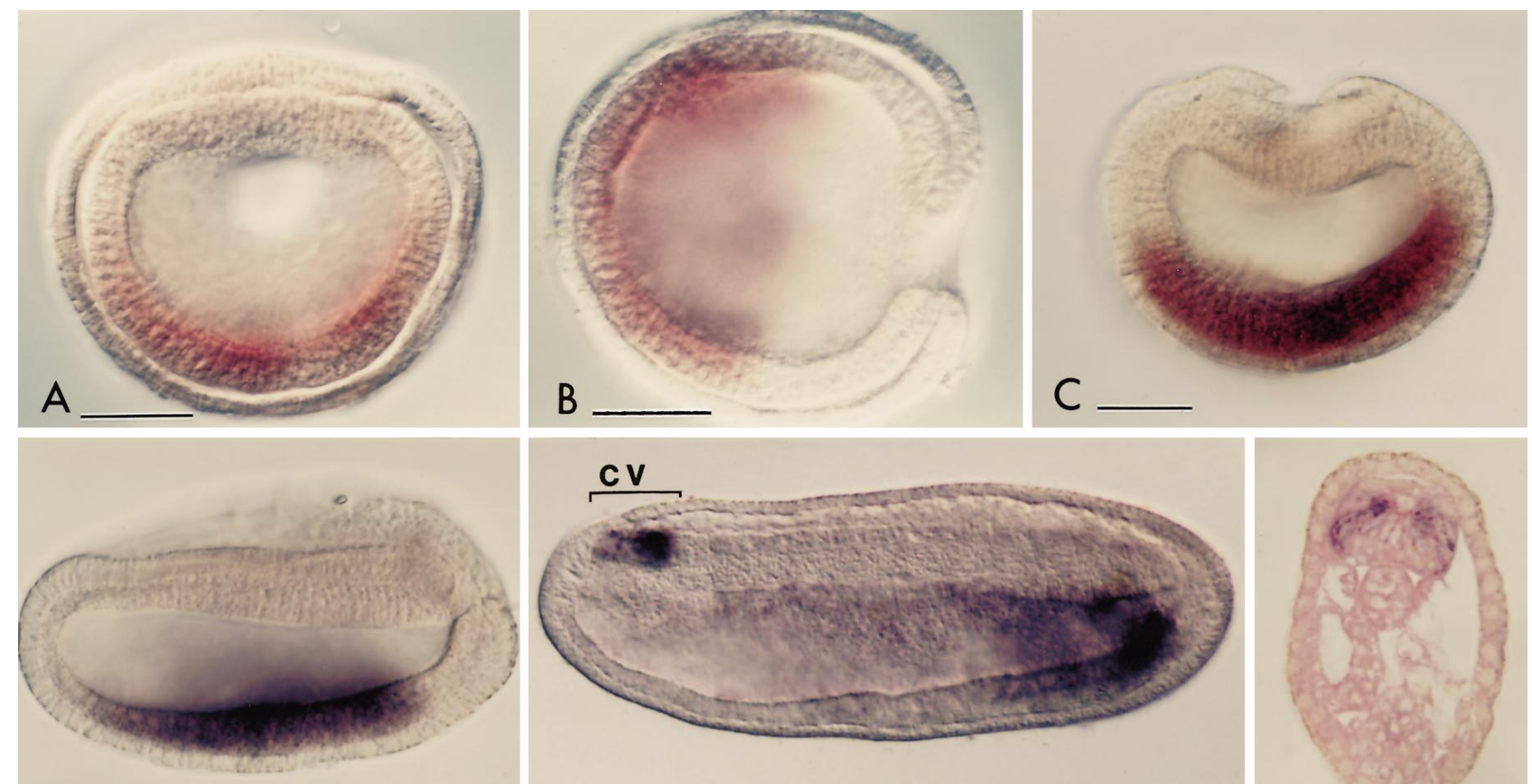

D

E
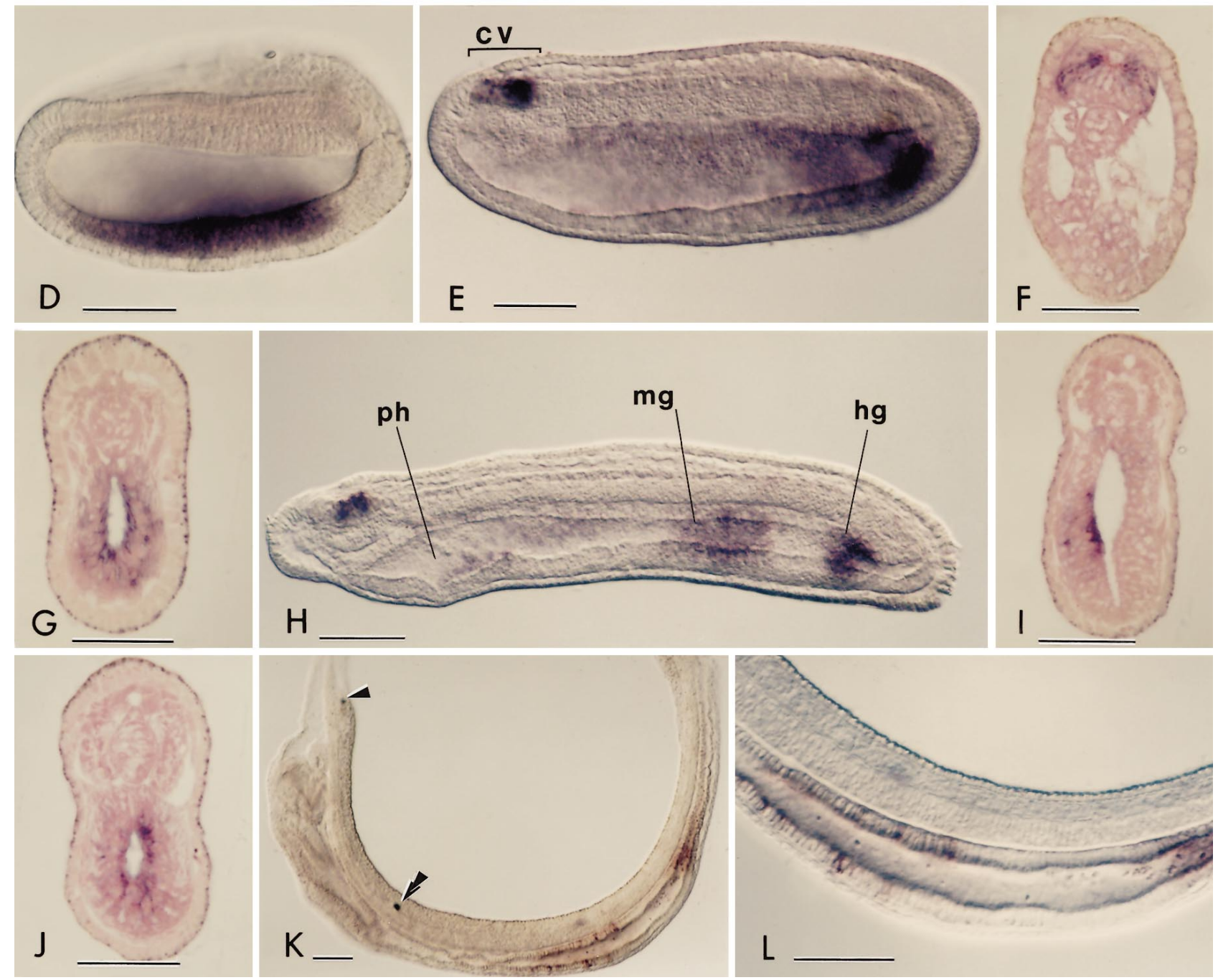

Fig. 2A-L Expression of AmphiNk2-2 in amphioxus embryos and larvae in whole mounts (anterior toward left) and cross sections (counterstained pink; dark material in epidermal cells comprises pigment granules and not gene expression; scale lines $50 \mu \mathrm{m}$ for whole mounts, $25 \mu \mathrm{m}$ for sections). A Late gastrula viewed from posterior (=vegetal) pole showing expression in ventral endoderm. B Preceding specimen viewed from dorsal side showing expression in anterior and ventral (out of focus) endoderm. C Early neurula viewed from posterior pole showing expression in ventral endoderm. D Preceding specimen in lateral view showing expression in ventral endoderm, excepting its most anterior and posterior regions. E Mid neurula in lateral view with neural expression in cerebral vesicle (anteroposterior extent indicated by bracket labeled $c v$ ) and endodermal expression that is strongest posteriorly (right center). $\mathbf{F}$ Cross section of preceding specimen through level of neural expression; ventrolateral cells on either side of cerebral vesicle contain conspicuous transcripts of AmphiNk2-2. G Cross section of mid

neurula through level of strong endodermal expression; transcripts conspicuous in cells all around perimeter of gut lumen. $\mathbf{H}$ Lateral view of late neurula showing neural expression in cerebral vesicle at top left and endodermal expression in three zones (weak in the pharynx, $p h$; intermediate in the midgut, $m g$; and strong in the hindgut, $h g$ ). I Cross section of preceding specimen through the level of pharyngeal expression; only cells on left side of the gut lumen contain detectable transcripts. J Cross section of late neurula through level of midgut; expression is visible in cells all around perimeter of gut lumen. K Lateral view of three-gill slit larva; neural expression no longer detectable (dark spots in nervous system are primary and anterior pigment spots, indicated by tandem arrowheads and single arrowhead, respectively); in gut, pharyngeal expression is no longer visible, but transcripts are detectable in scattered midgut cells and more generally in the hindgut epithelium. L Lateral view of posterior region of preceding specimen with midgut on the left and hindgut on the right 
(Fig. 2C), although not in its most anterior and posterior regions (Fig. 2D).

By the mid neurula stage (14 h), the embryo is elongating and the neural plate has rolled up into a dorsal hollow nerve cord (Fig. 2E). Endodermal expression of AmphiNk2-2 continues and neural expression has commenced in the anteriorly dilated portion of the nerve cord, which is called the cerebral vesicle (cv in Fig. 2E). Detectable expression extends along the middle $75 \%$ of anteroposterior axis of the cerebral vesicle and is most intense posteriorly. A cross section at any level along the anteroposterior axis of the cerebral vesicle shows transcripts of AmphiNk2-2 in ventrolateral cells on either side (Fig. 2F). Serial sections show that the stripes of neural expression on either side stop short of the anterior end of the nerve cord and do not become confluent there. In mid neurulae, endodermal expression of AmphiNk2-2 is most intense posteriorly in the gut (Fig. 2E); cross sections show that this expression is no longer exclusively ventral, but occurs in epithelial cells all around the perimeter of the gut lumen (Fig. 2G).

In the late neurula $(17 \mathrm{~h})$, the expression domains of AmphiNk2-2 remain conspicuous in the cerebral vesicle and endoderm (Fig. 2H). There are now three zones of endodermal expression, which are, from anterior to posterior: the pharynx, midgut and hindgut. The pharyngeal expression appears least intense in whole mounts, because the domain is chiefly limited to a few cells on the left side of the gut (Fig. 2I). In contrast, cross sections of the midgut and hindgut show that transcripts occur in cells all around the perimeter of the lumen (Fig. 2J).

During the next few days of development, about the time when the mouth and the first two gill slits open, transcripts of AmphiNk2-2 are still detectable in the cerebral vesicle and in the gut cells of the pharynx, midgut and hindgut. However, in the three-gill slit larva (5 days), expression is no longer seen in the cerebral vesicle and pharynx, but is still detectable in cells of the midgut and hindgut (Fig. 2K, L). At this stage, only a few midgut cells express AmphiNk2-2, although at high levels. In contrast, most of the cells in the anterior half of the hindgut express the gene, but at considerably lower levels. In larvae more than 1 week old, no further expression can be detected by whole-mount in situ hybridization.

In the developing gut of amphioxus, the early pattern of AmphiNk2-2 expression during the neurula stage indicates that the gene may be involved in regionalizaton of the digestive tract along the anteroposterior axis. The non-expressing region between the midgut and hindgut evidently corresponds to the ileo-colonic ring that separates those regions in the adult amphioxus. In the developing pharynx, detectable expression of AmphiNk2-2 is largely limited to the left side. However, AmphiNk2-2 does not appear to be one of the more up-stream genes determining the left-right axis, because the asymmetric expression appears only after the gut shows morphological evidence of left-right asymmetry. For example, rudiments of the endostyle (a thyroid homolog) and the mouth, respectively, are already present on the right and left sides of the pharynx (Conklin 1932).
In early larvae of amphioxus, detectable transcription of AmphiNk2-2 in the midgut epithelium becomes limited to a relatively few cells that express the gene intensely. This pattern suggests that AmphiNk2-2 may function later in amphioxus gut development for establishing and maintaining the differentiated state in specific cell types. Vertebrate $N k \times 2-2$ is expressed in the pancreas and in pancreatic islet alpha- and beta-cell lines (Rudnick et al. 1994). In vertebrate pancreatic islets, alpha-cells produce glucagon and beta-cells produce insulin. In adult amphioxus, there are scattered cells in the midgut epithelium that produce either glucagon or insulin (Reinecke 1981). Although it is not known whether amphioxus midgut cells expressing AmphiNk2-2 are the same ones containing glucagon and insulin, it may be that $N k \times 2-2$ homologs have an ancient and conserved role in the differentiation of cells producing these hormonal peptides.

Amphioxus AmphiNk2-2 is transcribed only at the anterior end of the neural tube, unlike its Drosophila and vertebrate homologs, which are transcribed along the entire neuraxis. For Drosophila vnd, although the more posterior neural expression has been much studied (Jiménez et al. 1995; Mellerick and Nierenberg 1995; Nierenberg et al. 1995; Bier 1997), little attention has been given to the most anterior (procephalic) region. For vertebrate $N k x 2-2$, however, expression has been well studied for all parts of the central nervous system (Price et al. 1992; Saha et al. 1993; Barth and Wilson 1995; Shimamura et al. 1995; Ericson et al. 1997), and these data can more readily be compared with the neural expression of AmphiNk2-2. Vertebrate Nkx2-2 is expressed in two bilateral stripes through all the brain regions and spinal cord. In the vertebrate hindbrain and spinal cord, these stripes run ventrally, on either side of the floorplate (Shimamura et al. 1995), and the gene specifies a ventral class of motor neurons (Ericson et al. 1997). By contrast, in the vertebrate fore- and midbrain, the expression stripes run along the boundary apparently dividing the more dorsal alar region from the more ventral basal region (Shimamura et al. 1995), and it has been suggested that the gene may function in determining positional or boundary information (Saha et al. 1993) and in regulating neuronal differentiation (Barth and Wilson 1995).

In contrast to vertebrate $N k x 2-2$, the neural expression of amphioxus AmphiNk2-2 is never detected in the developing nerve cord posterior to the cerebral vesicle. These posterior regions of the amphioxus nerve cord, which are thought to be homologs of the vertebrate hindbrain and spinal cord (Holland et al. 1994), are unusual in having ventral motor neurons that never send axons to the body wall muscles; instead the muscles send cytoplasmic extensions to neuromuscular junctions located on the surface of the nerve cord (Flood 1966). It is possible that the absence of detectable AmphiNk2-2 expression in the ventral motor neurons of amphioxus is correlated with their lack of axons extending beyond the bounds of the central nervous system.

The neural expression of amphioxus AmphiNk2-2 is detected only in the cerebral vesicle, most of which is probably homologous to the diencephalic forebrain of 


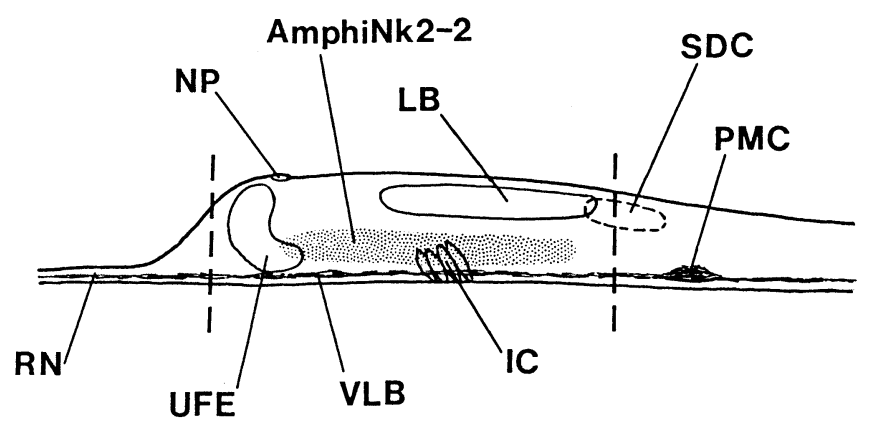

Fig. 3 Diagrammatic side view of anterior part of neural tube of larval amphioxus. Anterior toward left; cerebral vesicle limits indicated by vertical dashed lines. Stippling indicates position of basal ends of the neural cells expressing AmphiNk2-2. Landmark structures are based on microanatomical studies of Lacalli et al. (1994) and Lacalli (1996). In the following list, presumed homologies within the vertebrate diencephalon are indicated in parentheses after each structure: $I C$ infundibular cells (infundibulum of vertebrate pituitary), $L B$ lamellar body (vertebrate epiphysis), $N P$ neuropore, $P M C$ primary motor center, $R N$ rostral nerve, $S D C$ small dorsal cells, UFE unpaired frontal eye (vertebrate paired lateral eyes), $V L B$ ventrolateral bundle (vertebrate tract of the postoptic commissure)

vertebrates on the basis of computer assisted, 3D reconstructions of serial electron micrographs of Lacalli et al. (1994) and Lacalli (1996); the presumed homologous structures are diagrammed in Fig. 3, which also includes the neural expression domain of AmphiNk2-2. Limitation of neural expression to the cerebral vesicle suggests that the gene defines positional information along the anteroposterior axis of the nervous system. The gene might also define positional information along the dorsoventral axis of the nervous system, because AmphiNk2-2 transcripts are limited to a ventrolateral band of cells on either side of the midline; a similar pattern is seen for $N k x 2-2$ in the vertebrate diencephalon (Shimamura et al. 1995). In amphioxus, there is no obvious anatomical boundary separating an alar and a basal region along the dorsoventral axis of the cerebral vesicle. Nevertheless, it is possible that the expression domain of AmphiNk2-2 runs along a boundary homologous to that of $N k \times 2-2$ in the vertebrate forebrain.

During development of the amphioxus central nervous system, the earliest axon tracts appear on either side of the amphioxus cerebral vesicle. Lacalli et al. (1994) proposed that these tracts are homologous to the tract of the postoptic commisure (TPOC), which runs anteroposteriorly on either side of the developing vertebrate forebrain (Wilson et al. 1990). In the vertebrates, some of the axons in these tracts apparently arise from cells within the zone of $N k x 2-2$ expression and trace a course parallel to it; therefore, $N k x 2-2$ may help establish and maintain the differentiated identity of neurons giving rise to the TPOC and might also play a role in axon guidance (Barth and Wilson 1995). In amphioxus, the earliest axon tracts also trace a course along the ventral edge of the domain of AmphiNk2-2, which, like its vertebrate homologs, might function in neuronal cell specification and axon guidance.
For amphioxus, nothing definite is yet known about the upstream regulators and downstream targets of AmphiNk2-2. However, for vertebrates, it is known that neural expression of $N k x 2-2$ is under the control of Sonic hedgehog and Pax-6 (Ericson et al. 1997). In the vertebrate diencephalon, Sonic hedgehog transcription is most intense just ventral to the expression domains of $N k x 2-2$ (Shimamura et al. 1995), and experimental manipulation of the former influences the position of the latter (Barth and Wilson 1995). Thus, in the amphioxus forebrain, it seems likely that an amphioxus homolog of Sonic hedgehog acts upstream from AmphiNk2-2. Amphioxus may prove to be a useful model for elucidating such gene interactions, because both its anatomy and its genome are vertebrate-like, yet relatively simple.

Acknowledgements We are deeply indebted to John M. Lawrence for laboratory facilities at the University of South Florida and to Dr. David Mindale and his staff for help with the automated sequencing at the University of Michigan. This work was supported in part by NSF research grant IBN 96-309938 to NDH and LZH and in part by NIH research grants NS 29119-04 (NINDS) and HL 54732-01 (NHBL) to RB.

\section{References}

Barth KA, Wilson SA (1995) Expression of zebrafish $n k 2.2$ is influenced by sonic hedgehog/vertebrate hedgehog-1 and demarcates a zone of neuronal differentiation in the embryonic forebrain. Development 121:1755-1768

Bier E (1997) Anti-neural-inhibition: a conserved mechanism for neural induction. Cell 89:681-684

Bodmer R (1993) The gene tinman is required for specification of heart and visceral muscles in Drosophila. Development 118:719-729

Bodmer R (1995) Heart development in Drosophila and its relationship to vertebrates. Trends Cardiovasc Med 5:21-28

Bürglin TR (1994) A comprehensive classification of homeobox genes. In: Duboule D (ed) Guidebook to the homeobox genes, Oxford University Press, Oxford, pp 27-71

Conklin EG (1932) The embryology of amphioxus. J Morphol $54: 69-151$

De Robertis EM, Sasai Y (1996) A common plan for dorsoventral patterning in Bilateria. Nature 380:37-40

Ericson J, Rashbass P, Schedl A, Brenner-Morton S, Kawakami A, Heyningen G van, Jessell TM, Briscoe J (1997) Pax6 controls progenitor cell identity and neuronal fate in response to graded Shh signaling. Cell 90:169-180

Flood PF (1966) A peculiar mode of muscular innervation in amphioxus: light and electron microscopic studies of the socalled ventral roots. J Comp Neurol 126:181-218

François V, Bier E (1995) Xenopus chordin and Drosophila short gastrulation genes encode homologous proteins functioning in dorso-ventral axis formation. Cell 80:19-20

Garcia-Fernàndez J, Baguna J, Salo E (1991) Planarian homeobox genes: cloning sequence analysis, and expression. Proc Natl Acad Sci USA 88:7338-7342

Grens A, Gee L, Fisher DA, Bode HR (1996) CnNK-2, an NK-2 homeobox gene has a role in patterning the basal end of the axis in hydra. Dev Biol 180:473-488

Hartigan DJ, Rubenstein JLR (1996) The cDNA sequence of murine $N k x-2.2$. Gene 168:271-272

Harvey RP (1996) NK-2 homeobox genes and heart development. Dev Biol 178:203-216

Holland LZ, Holland PWH, Holland ND (1996) Revealing homologies between body parts of distantly related animals by in situ hybridization to developmental genes: amphioxus vs. ver- 
tebrates. In: Ferraris JD, Palumbi SR (eds) Molecular zoology: advances, strategies, and protocols. Wiley-Liss, New York, pp 267-282

Holland ND, Holland LZ (1993) Embryos and larvae of invertebrate deuterostomes. In: Stern CD, Holland PWH (eds) Essential developmental biology. IRL Press, Oxford, pp 21-32

Holland PWH, Garcia-Fernàndez J, Holland LZ, Williams NA, Holland ND (1994) The molecular control of spatial patterning in amphioxus. J Mar Biol Assoc UK 74:49-60

Jiménez F, Martin-Morris LE, Velasco L, Chu H, Sierra J, Rosen DR, White K (1995) vnd, a gene required for early neurogenesis of Drosophila, encodes a homeodomain protein. EMBO J 14:3487-3495

Jones CM, Smith JC (1995) Revolving vertebrates. Curr Biol 5: $574-576$

Lacalli TC (1996) Frontal eye circuitry, rostral sensory pathways and brain organization in amphioxus larvae: evidence from 3D reconstructions. Philos Trans R Soc London Ser B 351:243-263

Lacalli TC, Holland ND, West JE (1994) Landmarks in the anterior central nervous system of amphioxus larvae. Philos Trans R Soc London Ser B 344:165-185

Mellerick DM, Nierenberg M (1995) Dorsal-ventral patterning genes restrict $N K-2$ homeobox gene expression to the ventra half of the central nervous system of Drosophila embryos. Dev Biol 171:306-316

Nardelli-Haefliger D, Shankland M (1993) Lox10, a member of the $N K-2$ homeobox gene class, is expressed in a segmental pattern in the ectoderm and in the cephalic nervous system of the leech Helobdella. Development 118:877-523

Nierenberg M, Nakayama K, Nakayama N, Kim Y, Mellerick D, Wang LH, Webber KO, Lad R (1995) The NK-2 homeobox gene and the early development of the central nervous system of Drosophila. Ann NY Acad Sci 758:224-242

Okkema PG, Fire A (1994) The Caenorhabditis elegans NK-2 class homeoprotein CEH-22 is involved in combinatorial activation of gene expression in pharyngeal muscle. Development 129:2175-2186

Price M, Lazzaro D, Pohl T, Mattei MG, Rüther U, Olivo, JC, Duboule D, Di Lauro R (1992) Regional expression of the homeobox gene $N k x-2.2$ in developing mammalian forebrain. Neuron 8:241-255

Reinecke M (1981) Immunohistochemical localization of polypeptide hormones in endocrine cells of the digestive tract of Branchiostoma lanceolatum. Cell Tissue Res 219:445-456

Rudnick A, Ling TY, Odagiri H, Rutter WJ, German MS (1994) Pancreatic beta cells express a diverse set of homeobox genes. Proc Natl Acad Sci USA 91:12203-12207

Saha MS, Michel RB, Gulding KM, Grainger RM (1993) A Xenopus homeobox gene defines dorsal-ventral domains in the developing brain. Development 118:193-202

Seimiya M, Ishiguro H, Miura K, Watanabe Y, Kurosawa Y (1994) Homeobox-containing genes in the most primitive metazoa, the sponges. Eur J Biochem 221:219-225

Shimamura K, Hartigan DJ, Martinez S, Puelles L, Rubenstein JLR (1995) Longitudinal organization of the anterior neural plate and neural tube. Development 121:923-3933

Wada H, Satoh N (1994) Details of the evolutionary history from invertebrates to vertebrates, as deduced from the sequence of 18 S rDNA. Proc Natl Acad Sci USA 91:1801-1804

Wilson SW, Ross L, Parrett T, Easter SS (1990) The development of a simple scaffold of axon tracts in the brain of the embryonic zebrafish, Brachydanio rerio. Development 110:121-145 